\title{
The Effect of Hypercarbia on Age-Related Changes in Cerebral Glucose Transport and Glucose-Modulated Agonal Glycolytic Rates
}

\author{
RONALD J. T. CORBETT, ABBOT R. LAPTOOK, RICK STERETT, GREG TOLLEFSBOL, AND \\ DAMIAN GARCIA \\ Ralph Rogers and Mary Nell Magnetic Resonance Center, Department of Radiolog! [R.J.T.C.J and Pediatrics \\ [A.R.L., R.S., G.T., D.G.], University of Texas Southwestern Medical Center, Dallas, Texas 75235-9085
}

\begin{abstract}
This study examined the effect of hypercarbia on cerebral agonal glycolytic rates and brain lactate accumulation after complete ischemia induced by cardiac arrest. Before cardiac arrest, the blood plasma glucose concentration in seven newborn (113 d postconception; normal gestation, $115 \mathrm{~d}$ ) and seven 1-mo-old (144 d postconception) piglets was adjusted to a specific value (range, 1 to $64 \mathrm{mM}$ ), and then inspired ventilation gases were changed to $10: 50: 40 \mathrm{CO}_{2}: \mathrm{O}_{2}: \mathrm{N}_{2}$ for $20 \mathrm{~min}$. The agonal glycolytic rate was measured by monitoring the rate of cerebral lactate formation in vivo using proton nuclear magnetic resonance spectroscopy, and postmortem brain lactate concentrations were measured biochemically in tissue extracts obtained 40 to $45 \mathrm{~min}$ after cardiac arrest. These data were compared with 21 normocarbic piglets of similar age, nine examined as part of the present study and 12 examined previously (Corbett RJT, Laptook AR, Ruley JI, Garcia D: Pediatr Res 30:579-586, 1991). There was a nonlinear relationship between the final postmortem brain lactate concentration and preischemia blood plasma glucose concentration that was most prominent in newborn piglets and previously had gone unnoticed. When analyzed using a steady-state model for glucose transport, this relationship revealed that normocarbic newborns had a lower preischemia affinity constant for the transport mechanism for glucose $(2.8 \pm 1.5 \mathrm{mM})$ and lower cerebral glucose utilization rate relative to transport rate $(0.12 \pm 0.04)$, compared with 1 -mo-olds $(4.5 \pm 1.4 \mathrm{mM}$ and $0.30 \pm 0.03$, respectively). In the presence of hypercarbia, these differences diminish, suggesting that newborn and 1 -mo-olds had nearly identical affinity constants of transport mechanism for glucose $(3.7 \pm 0.8$ and $4.0 \pm 0.4 \mathrm{mM}$, respectively) and identical cerebral glucose utilization rate relative to transport rate $(0.21 \pm 0.03$ and $0.23 \pm 0.01$, respectively). For 1-mo-olds, hypercarbia substantially decreased the maximal rate of agonal glucose utilization $(3.93 \pm 0.55$ to $\left.1.75 \pm 0.11 \mu \mathrm{mol} \cdot \mathrm{g}^{-1} \cdot \mathrm{min}^{-1}\right)$ and decreased the concentration of plasma glucose $(6.86 \pm 3.00$ to $1.27 \pm 0.41 \mathrm{mM})$ at which the half maximal rate of utilization occurs, whereas in newborns the relative decrease produced by hypercarbia was not as prominent $(1.46 \pm 0.14$ to $1.12 \pm$ $0.22 \mu \mathrm{mol} \cdot \mathrm{g}^{-1} \cdot \mathrm{min}^{-1}$ and $0.93 \pm 0.66$ to $0.80 \pm 1.14 \mathrm{mM}$, respectively). To the extent that lactic-acidosis enhances irreversible tissue damage, hypercarbia could be beneficial
\end{abstract}

Received November 30, 1992; accepted April 23, 1993.

Correspondence and reprint requests: Ron Corbett, Department of Radiology, 5801 Forest Park Road, University of Texas Southwestern Medical Center, Dallas, TX 75235-9085.

Supported by 90 G-075 and 92R-075 Grant-in-Aids awarded by the American Heart Association Texas Affiliate, and Southwestern In I'wo Biotechnology Resource Facility Grant 5-P41-RR02584. for either age group because hypercarbia reduces both agonal glycolytic rate and brain tissue glucose concentration in newborns and substantially decreases agonal glycolytic rate in 1-mo-olds. (Pediatr Res 34: 370-378, 1993)

\section{Abbreviations}

AGR, initial agonal glycolytic rate during complete ischemia

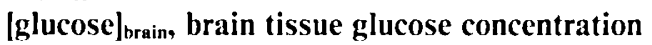

[glucose $\left.\right|_{\text {plasma, }}$ arterial blood plasma glucose concentration HCT, hematocrit

HR, heart rate

${ }^{1} \mathrm{I}$ NMR, proton nuclear magnetic resonance

$k_{\text {lac }}$, first-order rate constant for lactate accumulation

$K_{m}$, blood plasma glucose concentration where glycolytic rate is half maximal

$K_{l}$, affinity constant of transport mechanism for glucose [lactate $]_{\text {final }}$, final postmortem brain lactate concentration [lactate $]_{\text {initial, }}$ preischemia brain lactate concentration [lactate $\left.\right|_{\text {plasma, }}$ blood plasma lactate concentration MAP, mean arterial blood pressure

$T_{\text {max }}$ maximal cerebral glucose transport rate before ischemia

$V_{\text {Rlu }}$, cerebral glucose utilization rate before ischemia

$\mathrm{V}_{\mathrm{max}}$, maximum initial AGR during complete ischemia

pH $\mathrm{H}_{\mathrm{a}}$, arterial blood $\mathrm{pH}$

NMIR, nuclear magnetic resonance

$\mathrm{pH}_{\text {intracellular, intracellular brain } \mathrm{pH}}$

Lactic acidosis associated with ischemia or hypoxic-ischemia in the presence of hyperglycemia is thought to enhance irreversible brain tissue damage (1). However, hypercarbia also frequently occurs as a component of hypoxic-ischemic encephalopathy in newborns (2). It has been suggested that elevated tissue $\mathrm{CO}_{2}$ could have a beneficial moderating effect on biochemical disturbances associated with hypoxia, ischemia, or seizures (3). This hypothesis stems from the observation that hypercapnia slows the cerebral metabolic rate for glucose consumption (3). If the rate of lactate accumulation during ischemia is also slowed by hypercarbia, then intracellular tissue acidosis formed in parallel with lactate production will be reduced, thereby diminishing irreversible damage associated with acidosis (1). However, with the exception of one study (4), the observation that hypercapnia reduces glucose utilization is based on measurements of the uptake and turnover of radioactively labeled glucose or analogues in well-perfused brain under aerobic conditions. During complete ischemia, brain tissue oxygen tension rapidly drops to zero 
and glycolytic rates are accelerated by an order of magnitude ( 5 , 6). It is unclear whether hypercarbia slows AGR during anaerobic conditions to the same extent as observed during aerobic conditions. A second consideration is that [glucose] brain is increased by hypercarbia $(2,7)$. Therefore, the presence of hypercarbia and hyperglycemia may combine to increase lactic acidosis during ischemia. Furthermore, it has been demonstrated that in newborn swine (8) and adult rabbit brain (9), AGR is enhanced by increased [glucose] plasma. It is conceivable that the putative beneficial effect of hypercarbia on reducing AGR could be offset if an elevated [glucose] $]_{\text {brain }}$ also increases AGR or the degree of tissue lactic acidosis. The effect of hypercarbia on glycolysis is further complicated by the observation that the [glucose] $]_{\text {plasma }}$ for $\mathrm{K}_{\mathrm{m}}$ is lower for newborn piglets compared with 1-mo-old piglets, and therefore the rate of lactate formation in newborns is not as strongly accelerated by hyperglycemia in the former compared with the latter (8). Overall, these considerations make it difficult to predict what effect hypercarbia has on [glucose] $]_{\text {train }}$ and on AGR in the developing brain.

The objective of the present study was to evaluate the effects of hypercarbia on brain glucose transport and AGR in developing swine brain over a range of [glucose] plasma. This investigation was performed in newborn and 1-mo-old animals because our previous study showed that significant increases in cerebral energy metabolism occur over this period (8). The specific questions addressed are does cerebral glucose transport change with increased age, does hypercarbia affect glucose transport, and does hypercarbia affect glucose-modulated cerebral glycolytic rates and are there age-related differences?

\section{MATERIALS AND METHODS}

Experimental Protocol. The surgical procedures and experimental protocol were approved by the University of Texas Southwestern Medical Center Institutional Review Board for Animal Research. A total of 14 miniature swine (Sinclair strain) from five different litters were studied during hypercarbia. To evaluate the effects of hypercarbia, we have made extensive comparisons with normocarbic newborn and 1-mo-old piglets who were exposed to the same protocol as described below, except that $\mathrm{CO}_{2}$ was not included in the inhalation gases. Some results for normocarbic newborns $(n=6)$ and 1 -mo-old piglets $(n=6)$ were described previously (8). To further examine the relationship between [glucose] $]_{\text {plasma }}$, [glucose] brain, and AGR, five additional newborn $(n=11)$ and four 1 -mo-old piglets $(n=10)$ were studied during normocarbia.

The piglets studied during hypercarbia were divided into two groups at postconceptual ages ranging from 113 to $114 \mathrm{~d}$ (newborn) and 141 to $148 \mathrm{~d}(1$-mo-old). Normal term gestation for this species is $115 \mathrm{~d}$. For all five litters, birth was initiated after 111 to $112 \mathrm{~d}$ gestation via prostaglandin-induced labor (10) as described previously (8). On the day of the study, an animal was surgically prepared, wrapped in a blanket warmed with circulating water, placed in the magnet, and allowed to attain stable blood gas readings and rectal temperature of $38^{\circ} \mathrm{C}$ during a $1-\mathrm{h}$ period before collecting control data. Control data to assess baseline brain lactate levels and systemic physiologic status consisted of a ' $\mathrm{H}$ NMR spectrum, the drawing of a blood sample to measure $\mathrm{PO}_{2}$ and $\mathrm{PCO}_{2}$ tensions, $\mathrm{pH}_{\mathrm{a}}$ and $\mathrm{HCT}$, plasma glucose and lactate concentrations, and the recording of $\mathrm{HR}$ and MAP. Next, a continuous i.v. infusion of glucose $\left(10\right.$ to $50 \mathrm{mg} \cdot \mathrm{kg}^{-1}$. $\left.\mathrm{min}^{-1}\right)$, or bolus injection of insulin ( 2 to $4 \mathrm{IU} / \mathrm{kg}$ ) was given to adjust the [glucose $]_{\text {plasma }}$ of individual piglets to a predesignated value in the range of 1 to $64 \mathrm{mM}$. In a previous study (8), we determined that 30 to $40 \mathrm{~min}$ was sufficient for [glucose] plasma to reach a steady state. In the present study, blood samples to monitor blood gases and substrate concentration were drawn 30 to $40 \mathrm{~min}$ after the injection of insulin or infusion of glucose. This was followed by $20 \mathrm{~min}$ of hypercarbia, achieved by altering the ventilation gases to $8-10: 50: 42-40, \mathrm{CO}_{2}: \mathrm{O}_{2}: \mathrm{N}_{2}$. Blood sam- ples were obtained at one or two intervals during hypercarbia (see Results). Two min after the final blood sample measured during hypercarbia, complete cerebral ischemia was induced via cardiac arrest by an i.v. injection of $4 \mathrm{~mL}$ of $4 \mathrm{M} \mathrm{KCl}$ directly to the heart. The rate of lactate accumulation was measured by collecting 50 individual ${ }^{1} \mathrm{H}$ NMR spectra every $0.6 \mathrm{~min}$ for 30 min, starting $1 \mathrm{~min}$ before cardiac arrest. At $29 \mathrm{~min}$ after cardiac arrest, NMR data collection was terminated and the animal was removed from the magnet. The portion of the cerebral cortex immediately below the NMR coil was removed 40 to $45 \mathrm{~min}$ postmortem, and stored at $-70^{\circ} \mathrm{C}$ for subsequent measurements of brain lactate concentration.

Animal Preparation. Short-acting anesthetics were used in the present study so that when experimental data collection began the affects of these agents on cerebral energy metabolism would be negligible. After premedication with ketamine (15 to $20 \mathrm{mg} /$ $\mathrm{kg}$, intramuscular) and infiltration of the surgical sites with $1 \%$ xylocaine, the animal was tracheotomized and ventilated with $70: 30 \quad \mathrm{~N}_{2} \mathrm{O}: \mathrm{O}_{2}$ (Harvard small animal respirator). Intravascular catheters were placed in the common carotid artery and right atrium via an external jugular vein. D-tubcurarine $\mathrm{Cl}(0.10 \mathrm{mg} /$ $\mathrm{kg})$ and nalbuphine $(0.15 \mathrm{mg} / \mathrm{kg})$ were administered i.v. for muscle relaxation and analgesia, respectively. A second injection of nalbuphine was given 15 to 60 min before initiating cardiac arrest. The presence of nalbuphine for analgesia during the experiment was not expected to affect cerebral metabolism because narcotic opiates can relieve pain but have no or only mild depressive effects on CNS activity (11). Skin overlying the skull was retracted so the NMR radiofrequency coil rested directly on the skull. After surgery, the animal was transported to the magnet and ventilated with $70: 30 \mathrm{~N}_{2}: \mathrm{O}_{2}$ and stabilized for $1 \mathrm{~h}$ before collecting control in vivo NMR and physiologic readings.

NMR Spectroscopy. Protocols for the collection and processing of 'H NMR data remained unaltered from our earlier report (8). Briefly, 'H NMR spectroscopy was performed using a General Electric Omega operating system and $40-\mathrm{cm}$-diameter bore 4.7 Tesla Oxford superconducting magnet. ${ }^{1} \mathrm{H}$ NMR spectra from the cerebral cortex were measured using a radiofrequency coil (5 $\times 3 \mathrm{~cm}$ ) tuned to $200 \mathrm{MHz}$. 'H NMR data were collected using a $1 \overline{3} 3 \overline{1}-\tau-2 \overline{6} 6 \overline{2}-\tau-A c$, spin-echo-pulse sequence, where "1" corresponds to the first portion of a binomial pulse equal to $1 / 8$ of the $90^{\circ}$ pulse width; the other pulses are multiples of this, and the bar indicates $180^{\circ}$-phase inversion. The prepulse delay time was $1 \mathrm{~s}$ and $\tau$, the delay time for echo formation, was $150 \mathrm{~ms}$. The accumulated free induction decay (16 transients collected every $36 \mathrm{~s}$ ) was processed by applying direct current offset baseline correction, a $10-\mathrm{Hz}$ exponential apodization function, Fourier transformation, and zero-order phasing. The phase angle applied was determined from the setting that gave the maximal positive peak for the final postmortem $\beta$-lactate 'H NMR signal. The ${ }^{1} \mathrm{H}$ NMR spectra measured at control were subtracted from all subsequent spectra collected during ischemia to yield difference spectra corresponding to the change in cerebral lactate concentration after cardiac arrest. The relationship between the in vivo NMR lactate signal height and brain lactate concentration was established by using the postmortem brain lactate NMR signal and tissue lactate concentration as a calibration factor (8). The validity of this method for measuring changes in brain lactate concentration has been previously discussed $(8,9,12)$. Briefly, the calibration relies on the assumption that the postmortem brain lactate concentration has reached a plateau after $30 \mathrm{~min}$ of ischemia, that the relaxation properties of the lactate'H NMR signal do not change during ischemia, and that there are no ${ }^{1} \mathrm{H}$ NMR signals from other compounds that could interfere with the quantitation of the signal from lactate. The data presented in Figure 1 were used to verify that brain lactate concentration had reached a plateau within $30 \mathrm{~min}$ using the same procedure described previously (8). Throughout this period, there were no significant changes in the line width of the lactate peak suggesting that the apparent spin-spin relaxation properties 


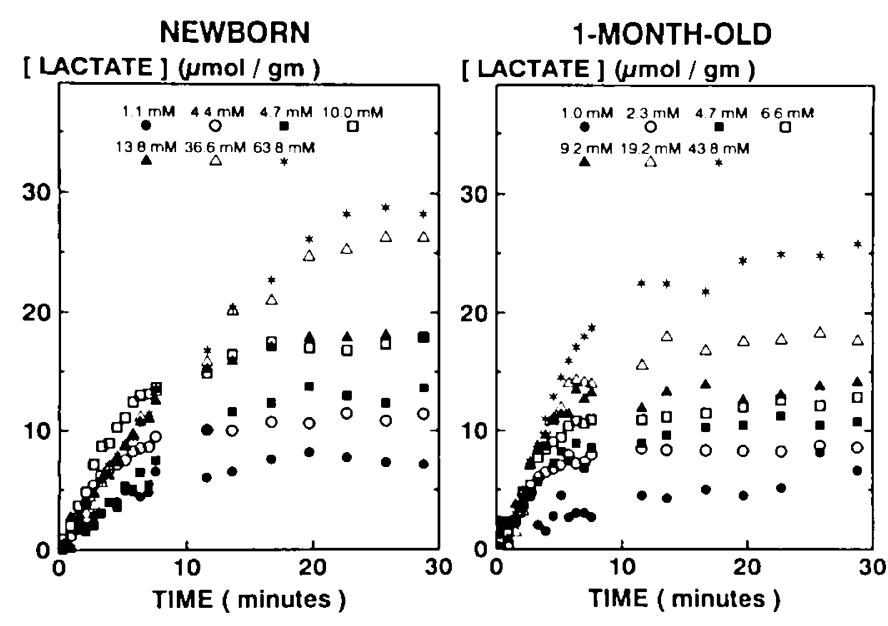
1-MONTH-OLD
[ LACTATE] $(\mu \mathrm{mol} / \mathrm{gm})$

Fig. 1. Rates of agonal lactate formation after complete ischemia. Plots of the change in lactate concentration versus time are shown for both hypercarbic newborn and 1-mo-old piglets. The blood plasma glucose concentration for individual piglets immediately before cardiac arrest (time $=0$ ) are indicated in the figure inset.

of the $\beta$-lactate protons do not change. The spin-lattice relaxation properties of the $\beta$-lactate protons do not change between control and ischemia insofar as that control brain lactate concentration derived from the postmortem calibration of the $\beta$-lactate ${ }^{1} \mathrm{H}$ NMR signal is in good agreement with brain lactate concentration measured from perchloric acid extracts made from brain tissue frozen under control conditions (13). Interference from the ${ }^{1} \mathrm{H}$ NMR signals of other compounds such as lipids and proteins was discounted because we used a long delay time (150 $\mathrm{ms}$ ) in the spin-echo-pulse sequence and because no peaks other than that from lactate at $1.33 \mathrm{ppm}$ were observed from 1.7 to $0.9 \mathrm{ppm}$ in ' $\mathrm{H}$ NMR difference spectra.

Physiologic Monitoring and Biochemical Measurements. MAP and $\mathrm{HR}$ were measured via the catheter in the carotid artery using a Gould (Cleveland, $\mathrm{OH}$ ) pressure transducer and a Coulbourn (Lehigh Valley, PA) polygraph. The catheter in the carotid artery also was used to obtain blood for monitoring $\mathrm{pH}_{\mathrm{a}}$, blood gases, [lactate $]_{\text {plasma }}$, [glucose $]_{\text {plasma }}$, and HCT. The catheter in the jugular vein was used for the administration of nalbuphine, glucose, insulin, and $4 \mathrm{M} \mathrm{KCl}$. The $\mathrm{pH}_{\mathrm{a}}, \mathrm{PCO}_{2}$, and $\mathrm{PO}_{2}$ were measured from a $200-\mu \mathrm{L}$ sample using an Instrumentation Laboratory model $1306 \mathrm{pH} /$ blood gas analyzer (Lexington, MA) blood gas analyzer. Plasma lactate concentration was measured using the lactate dehydrogenase assay after deproteinization of $200 \mu \mathrm{L}$ of plasma with $8 \%$ perchloric acid and centrifugation for $1 \mathrm{~min}$ at $1500 \times \mathrm{g}$. Plasma glucose was determined by the glucose oxidase/peroxidase assay after deproteinization of $50 \mu \mathrm{L}$ of plasma with $2 \%$ perchloric acid and centrifugation.

Frozen postmortem cortical brain samples (5 to $10 \mathrm{~g}$ per piglet) were ground to a powder and mixed thoroughly to ensure a homogeneous sample representative of the entire brain region measured by the NMR radio frequency coil. Brain tissue lactate concentrations were determined using the lactate dehydrogenase enzymatic assay of the neutralized aqueous portion from $0.5 \mathrm{~g}$ of brain powder, homogenized, and extracted in $5 \%$ perchloric acid (14).

Data Analysis. All statistical tests and regression fits were performed using SPSS/PC (Version 3.1, Statistical Package for the Social Sciences Inc., Chicago, IL), loaded on an AST Premium 286 personal computer (AST Research Inc., Irvine, CA), and upgraded with a Super SX-386 board (Super Computers Inc., Readmond, WA). Tests for differences between multiple groups were made by a one-way analysis of variance using Duncan's multiple comparison test (15) to identify statistically significant differences $(p<0.05)$ between specific pairs of means.

Cerebral glucose transport. Time-dependent changes in [glu- cose $]_{\text {hrain }}$ can be expressed as the sum of Michaelis-Menten equations (16):

$$
\begin{aligned}
\frac{\mathrm{d}[\text { glucose }]_{\text {hrain }}=}{\mathrm{dt}}= & \frac{\mathrm{T}_{\max } \cdot[\text { glucose }]_{\text {plasma }}}{[\text { glucose }]_{\text {plasma }}+\mathrm{K}_{\mathrm{t}}}- \\
& \frac{\mathrm{T}_{\max } \cdot[\text { glucose }]_{\text {brain }}}{[\text { glucose }}-\frac{\mathrm{V}_{\mathrm{glu}} \cdot[\text { glucose }]_{\text {brain }}}{[\mathrm{K}}
\end{aligned}
$$

The first term on the right-hand side of equation 1 represents glucose movement into the brain, the second term represents glucose movement out of the brain, and the third term represents glucose utilization by the brain. Brain glucose was evaluated indirectly by measuring the final concentration of brain lactate achieved after cardiac arrest. Analogous to earlier studies that used decapitation to induce complete ischemia (4-6), cardiac arrest converts the brain into a closed system in which all glucose and other glycosyl units are converted into lactate (see below). $T_{\max }$ equals the maximal rate of glucose transport; $K_{t}$ equals the affinity constant of glucose for the transport mechanism. $T_{\max }$ and $K_{t}$ represent the averaged transport properties of brain endothelial cells located on the luminal and contraluminal membranes (16). $V_{\text {glu }}$ and $K_{\text {hex }}$ are the Michaelis-Menten constants for glucose utilization, which are assumed to equal the maximal velocity and affinity constant for the hexokinase catalyzed conversion of glucose to glucose-6-phosphate, respectively. The affinity constant for glucose to hexokinase is assumed to equal approximately $0.05 \mathrm{mM}(16)$, and, therefore, $K_{\text {hex }} \ll$ [glucose] brain and the last term in equation 1 is approximately equal to $V_{\text {glu }}(16)$. The results presented below for hypercarbic animals and our previous study of normocarbic piglets (8) indicate that [glucose] plasma was constant for 10 to $20 \mathrm{~min}$ before ischemia; therefore, a steady state of glucose flux between brain tissue and blood plasma is assumed to exist for all animals. If [glucose] plasma is constant, then $\mathrm{d}$ [glucose] $]_{\text {brain }}$ divided by dt equals 0 , and equation 1 can be rearranged to give an expression with [glucose] brain on the left-hand side:

$$
\begin{aligned}
& \text { [glucose }_{\text {brain }}= \\
& \frac{\left.-\mathrm{K}_{\mathrm{t}}\left\{\left(\mathrm{V}_{\mathrm{glu}} / \mathrm{T}_{\text {max }}\right)-[\text { [glucose }]_{\text {plasma }} /\left(\mathrm{K}_{\mathrm{t}}+[\text { glucose }]_{\text {plasma }}\right)\right]\right\}}{1+\left\{\left(\mathrm{V}_{\mathrm{glu}} / \mathrm{T}_{\max }\right)-\left[[\text { glucose }]_{\text {plasma }} /\left(\mathrm{K}_{\mathrm{t}}+[\text { glucose }]_{\text {plasma }}\right)\right]\right\}}
\end{aligned}
$$

Nonlinear regression analysis using equation 2 was performed for sets of [glucose] $]_{\text {brain }}$ versus [glucose] $]_{\text {plasma }}$, measured for different groups of piglets to obtain best-fit estimates of $K_{t}$ and the ratio $\mathrm{V}_{\mathrm{glu}} / \mathrm{T}_{\max }$.

To estimate [glucose] brain, we have made the following two assumptions. The postmortem brain lactate concentration minus the control brain lactate concentration ([lactate $]_{\text {rinal }}$ ) equals two times the sum of preischemia intracellular concentrations of glucose plus endogenous nonglucose (glycogen and sugar phosphates) reserves of glycosyl units $\left([\text { glycosyl }]_{\text {initial }}\right)$. The intercept from a plot of postmortem lactate versus preischemia [glucose] plasma equals the sum of endogenous nonglucose glycosyl units present in brain tissue (see Results). If these assumptions are true, then:

$$
\text { [glucose }_{\text {brain }}=\left([\text { lactate }]_{\text {linal }}-\text { INTERCEPT }\right) / 2
$$

The numerator in equation 3 is divided by 2 because $2 \mathrm{~mol}$ of lactate are generated per mol of glucosyl unit consumed. The first assumption is justified given that cardiac arrest essentially converts the brain into a "closed system," with no exchange between blood and brain because blood flow is 0 (17). The second assumption implies that [glycosyl $]_{\text {initial }}$ is independent of

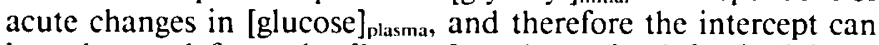
be subtracted from the [lactate] $]_{\text {final }}$ determined for individual animals with different [glucose $]_{\text {plasma }}$ at the point where complete ischemia is initiated (see Discussion).

Agonal glycolytic rates. The $\mathrm{k}_{\text {lac }}$ was determined by the analysis 
of the change in brain lactate concentrations ([lactate], measured at different times during the first $5 \mathrm{~min}$ after cardiac arrest using the following equation:

$$
[\text { lactate }]_{\mathfrak{t}}=[\text { lactate }]_{\text {final }}\left(1-\mathrm{e}^{\left(-k_{\text {lac }} \cdot t\right)}\right)
$$

where [lactate $]_{\text {final }}$ is equal to the postmortem brain lactate concentration minus control brain lactate concentration $(1.5 \mu \mathrm{mol}$. $\left.\mathrm{g}^{-1}\right)$ because the lactate signal at control is not represented in the ${ }^{1} \mathrm{H}$ NMR different spectra we used to measure lactate accumulation. Nonlinear regression analysis was performed to obtain the best estimate and SD of the rate constant for lactate production, $\mathrm{k}_{\mathrm{lac}}$. A discussion of the use of this model, the use of nonlinear regression analysis to evaluate $\mathrm{k}_{\mathrm{lac}}$, and an error analysis have been discussed previously (8).

The AGR equals the maximum rate of lactate production (i.e. [lactate $]_{\text {final }}$ multiplied by $\mathrm{k}_{\text {lac }}$ ) divided by 2 because two lactate molecules are produced per molecule of glucose consumed during glycolysis:

$$
\begin{array}{r}
A G R=-d[\text { glucose }]_{\text {brain }} / \mathrm{dt}=(\mathrm{d}[\text { lactate }] / \mathrm{dt}) / 2 \\
=\left([\text { lactate }]_{\text {final }} \cdot \mathrm{k}_{\text {lac }}\right) / 2
\end{array}
$$

AGR was related to the substrate concentration, [glucose] plasma, via the Michaelis-Menten equation:

$$
A G R=\left(V_{\max } \cdot[\text { glucose }]_{\text {plasma }}\right) /\left([\text { glucose }]_{\text {plasma }}+K_{m}\right)
$$

$\mathrm{V}_{\max }$ represents the maximal cerebral glycolytic rate with respect to blood glucose concentration, and $\mathrm{K}_{\mathrm{m}}$ is the apparent Michaelis-Menten constant for glucose corresponding to the [glucose] plasma where half maximal reaction velocity is reached. Nonlinear regression analysis was performed to obtain best-fit estimates of the parameters $\mathrm{V}_{\max }$ and $\mathrm{K}_{\mathrm{m}}$.

\section{RESULTS}

Physiologic readings. The mean physiologic readings for the newborn and 1 -mo-old piglets under control conditions and 18 \pm 2 min after inducing hypercarbia are summarized in Table 1 . One-mo-old piglets had significantly higher body weight, MAP, $\mathrm{PO}_{2}$, and lower [lactate] plasma, compared with newborns. With the exception of a slightly higher control [glucose $]_{\text {plasma }}$ and lower $\mathrm{PCO}_{2}$ for newborns (i.e. $1.3 \mathrm{kPa}$ ), the prehypercarbia control physiologic readings were not significantly different from the control physiologic readings for normocarbic newborn and 1 mo-old swine measured previously (8), or the nine additional normocarbia animals studied as part of the present study (data not shown). For both newborn and 1-mo-old piglets, changing the ventilation gas mixture to include 8 to $10 \% \mathrm{CO}_{2}$ resulted in a significant decrease in $\mathrm{pH}_{\mathrm{a}}$ and increase in $\mathrm{PCO}_{2}$ compared with control values. The magnitude of change in $\mathrm{pH}_{\mathrm{a}}$ and $\mathrm{PCO}_{2}$ did not differ between the two age groups. There also was a decrease in $\mathrm{HR}$ and an increase in MAP that were of similar magnitude for both age groups, and a slight decrease in $\mathrm{PO}_{2}$ for 1 -mo-old piglets. We judged that the slight alterations and differences in $\mathrm{HR}, \mathrm{MAP}$, and $\mathrm{PO}_{2}$ would have a negligible impact on cerebral energy metabolism measured during complete ischemia.

The measurement of glucose in blood plasma obtained at different stages in the protocol suggest that piglets had steady state levels of [glucose] $]_{\text {plasma }}$ for at least the full 20 -min exposure to $\mathrm{CO}_{2}$ in the ventilation gas mixture before ischemia. For a

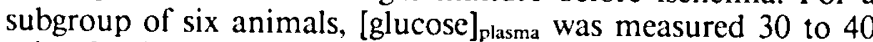
min after injecting insulin or infusing glucose and again $18 \mathrm{~min}$ after exposure to $\mathrm{CO}_{2}$; the difference between the two values was not significant (paired $t$ test). In a different subgroup of seven animals, two sets of physiologic readings were measured 12 and $18 \mathrm{~min}$ after exposure to $\mathrm{CO}_{2}$. There were no significant differences between any mean physiologic readings with the exception of slightly lower $\mathrm{pH}_{\mathrm{a}}$, which was 0.02 units lower after $18 \mathrm{~min}$ of hypercarbia compared with $12 \mathrm{~min}$ of hypercarbia (paired $t$ test, $p=0.007$ ). For one hypoglycemic 1 -mo-old animal, we were unable to draw an arterial blood sample during hypercarbia, and so we estimated [glucose] plasma $_{\text {to }}$ to equal $1 \mathrm{mM}$ based on a blood sample drawn $40 \mathrm{~min}$ after injecting insulin and from venous blood taken during hypercarbia.

After the injection of $\mathrm{KCl}, \mathrm{HR}$ dropped to 0 within one or two beats, with a concurrent drop in MAP, resulting in a welldefined point at which complete cerebral ischemia was initiated.

Kinetics of lactate formation. In vivo lactate- ${ }^{-} \mathrm{H}$ NMR spectra collected in the present study did not differ substantially in quality or signal-to-noise compared with spectra presented previously $(8,12)$. ${ }^{1} \mathrm{H}$ NMR difference spectra of hypercarbia minus control indicated no peaks detectable above the noise, suggesting that hypercarbia did not alter brain lactate concentrations to within the limits of detectability of the NMR measurement (approximately $1 \mu \mathrm{mol} \cdot \mathrm{g}^{-1}$ ). This is consistent with previous in vitro determinations of control lactate concentration from piglet brain frozen during normocarbia or hypercarbia, which revealed no significant differences from each other (1.5 versus $1.4 \mu \mathrm{mol}$. $\left.\mathrm{g}^{-1}\right)$ (13). Serial difference spectra collected after cardiac arrest (i.e. ischemia minus control) revealed a rapid increase in the lactate-'H NMR signal at $1.33 \mathrm{ppm}$ corresponding to the $\beta$ protons of lactate; no other peaks were present in the difference spectra. Within 20 to $29 \mathrm{~min}$, the lactate-' $\mathrm{H}$ NMR signal reached a plateau and NMR data collection was terminated.

\begin{tabular}{|c|c|c|c|c|}
\hline & \multicolumn{2}{|c|}{ Newborn $(n=7)$} & \multicolumn{2}{|c|}{ 1-mo-old $(n=7)$} \\
\hline & Pre- $-\mathrm{CO}_{2}$ & $\mathrm{CO}_{2}$ & Pre- $\mathrm{CO}_{2}$ & $\mathrm{CO}_{2}$ \\
\hline Age (days) & $113 \pm 1$ & & $144 \pm 3 \dagger$ & \\
\hline Wt $(\mathrm{kg})$ & $0.95 \pm 0.08$ & & $5.31 \pm 0.46 \dagger$ & \\
\hline$[\text { Glucose }]_{\text {plasma }}(\mathrm{mM})$ & $7.3 \pm 2.6$ & $1-64 \ddagger$ & $6.7 \pm 1.5$ & $1-44 \ddagger$ \\
\hline$[\text { Lactate }]_{\text {plasma }}(\mathrm{mM})$ & $2.2 \pm 0.6$ & $1.6 \pm 1.0$ & $1.4 \pm 0.4 \dagger$ & $1.4 \pm 0.6$ \\
\hline $\mathrm{pH}_{\mathrm{a}}$ & $7.44 \pm 0.06$ & $7.03 \pm 0.06 \S$ & $7.45 \pm 0.05$ & $7.04 \pm 0.02 \S$ \\
\hline $\mathrm{PCO}_{2}(\mathrm{kPa})$ & $4.8 \pm 0.3$ & $14.1 \pm 1.1 \S$ & $4.4 \pm 0.4$ & $13.6 \pm 0.9 \S$ \\
\hline $\mathrm{PO}_{2}(\mathrm{kPa})$ & $14.7 \pm 4.5$ & $15.6 \pm 3.3$ & $21.1 \pm 2.0 \dagger$ & $17.6 \pm 3.2 \S$ \\
\hline HCT (vol\%) & $29 \pm 8$ & $32 \pm 8$ & $36 \pm 4$ & $37 \pm 5$ \\
\hline $\mathrm{HR}$ (beats/min) & $234 \pm 24$ & $185 \pm 48 \S$ & $237 \pm 34$ & $192 \pm 32 \S$ \\
\hline $\mathrm{MAP}(\mathrm{mm} \mathrm{Hg})$ & $70 \pm 5$ & $83 \pm 12 \S$ & $99 \pm 12 \dagger$ & $138 \pm 5 \S \|$ \\
\hline
\end{tabular}

The approximately 40 -min postmortem [lactate $]_{\text {final }}$ measured in cortical brain tissue was used to calculate a calibration factor

Table 1. Comparison of physiologic data for newborn and 1-mo-old piglets before (pre- $\mathrm{CO}_{2}$ ) and during (CO $\left.\mathrm{C}_{2}\right)$ hypercapnia*

* Values are mean $\pm \mathrm{SD}$.

† Significant difference compared with mean measured for newborns before hypercarbia (unpaired $t$ test, $p<0.05$ ).

$\ddagger$ Ranges are given because [glucose] $]_{\text {plasma }}$ was adjusted by injecting insulin or infusing glucose before inducing hypercarbia (see Materials and Methods).

$\S$ Significant difference compared with prehypercarbia (paired $t$ test, $p<0.05$ ).

$\|$ Significant difference compared with mean for newborns during hypercarbia (unpaired $t$ test, $p<0.05$ ). 
to convert lactate- ${ }^{-} \mathrm{H}$ NMR signal measured at earlier times after cardiac arrest into a brain tissue lactate concentration (Fig. 1). Nonlinear regression analysis was used to fit equation 4 to the first $5 \mathrm{~min}$ of lactate versus time data sets to evaluate the $\mathrm{k}_{\mathrm{lac}}$. The $k_{\text {lac }}$ values corresponding to the best fit ranged from 0.067 to $0.22 \mathrm{~min}^{-1}$ for hypercarbic newborns and from 0.13 to 0.30 $\mathrm{min}^{-1}$ for hypercarbic 1-mo-old piglets. Previously, we had noted a negative linear correlation between $\mathrm{k}_{\text {lac }}$ and [glucose] $]_{\text {plasma }}$ for newborn normocarbic piglets but not for 1-mo-old piglets (8). Plots of $\mathrm{k}_{\text {lac }}$ versus [glucose] plasma $_{\text {(data not shown) suggested a }}$ trend $(p \approx 0.1)$ for a negative linear correlation for both hypercarbic newborns (slope $=-0.00167 \pm 0.001 \mathrm{~min}^{-1} / \mathrm{mM} ; r=$ -0.61 ) and 1-mo-old (slope $=-0.0029 \pm 0.0012 \mathrm{~min}^{-1} / \mathrm{mM} ; r$ $=-0.73$ ) piglets. These slopes were not significantly different from each other. The slopes of $\mathrm{k}_{\text {lac }}$ versus [glucose] ]lasma $_{\text {for }}$ hypercarbic newborn or 1-mo-old piglets were significantly lower than their normocarbic counterparts (Duncan multiple comparison test, $p<0.05$ ). The inclusion of data for two additional normocarbic animals in both age groups did not substantially alter the slopes for newborns (slope $=-0.0032 \pm 0.0006 \mathrm{~min}^{-1} /$ $\mathrm{mM} ; r=-0.90$ ) or 1 -mo-old piglets (slope $=+0.0003 \pm 0.0023$ $\mathrm{min}^{-1} / \mathrm{mM} ; r=0.05$ ) compared with our previous report (8).

Cerebral glucose transport. The increased number of animals and higher range of [glıcose $]_{\text {plasma }}$ examined in the present study revealed a nonlinear relationship between [lactate $]_{\text {final }}$ and [glucose $]_{\text {plasma }}$ that we previously did not detect (Fig. 2). This was most evident in either group of newborns. For [glucose] $]_{\text {plasma }}$ concentrations less than $20 \mathrm{mM}$, the formation of [lactate] final for a given prearrest [glucose] plasma was steep, as demonstrated by slopes of $0.91 \pm 0.15(n=9)$ and $0.87 \pm 0.14(n=5)$ for normocarbic and hypercarbic newborns, respectively. In contrast, slopes calculated using the full set of data were $0.58 \pm 0.07$ and $0.30 \pm 0.04$, respectively. The nonlinear relationship between [lactate $]_{\text {final }}$ and [glucose] $]_{\text {plasma }}$ was less pronounced for 1mo-old animals. Linear fits to the subset of data where [glucose] $_{\text {plasma }}<20 \mathrm{mM}$ gave a significantly higher slope compared with linear fits calculated using the full set of animals for

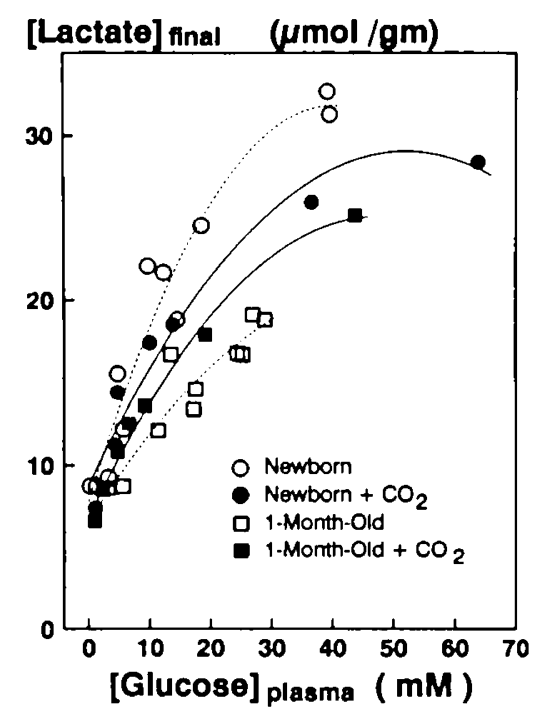

Fig. 2. The relationship between maximal brain lactate concentration $\left([\text { Lactate }]_{\text {final }}\right)$ and blood plasma glucose concentration ([Glucose $\left.]_{\text {plasma }}\right)$ for newborn (circles) and 1-mo-old piglets (squares) in the presence (closed symbols) and absence (open symbols) of hypercarbia. The solid lines represent the best fit of a second-order polynomial equation ( $\mathrm{A}$. [glucose $]_{\text {plasma }}{ }^{2}+B \cdot$ [glucose $]_{\text {plasma }}+C$ ) to each of the four groups. The $A$ and $B$ coefficients ranged from -0.015 to -0.0061 and from 1.2 to 0.59 , respectively. The intercept equaled $7.8 \pm 1.4,8.8 \pm 1.3,6.6 \pm 1.9$. and $6.8 \pm 0.6 \mu \mathrm{mol} \cdot \mathrm{g}^{-1}$ for newborn normocarbic, newborn hypercarbic, 1-mo-old normocarbic, and 1-mo-old hypercarbic groups, respectively. Regression coefficients ranged from 0.87 to 0.99 . hypercarbic 1 -mo-olds $(0.59 \pm 0.08$ versus $0.40 \pm 0.04)$ but not for normocarbic 1 -mo-olds $(0.43 \pm 0.08$ versus $0.39 \pm 0.06)$. To further test for nonlinearity, we compared fits obtained using a first-order (i.e. linear) equation versus a second-order (i.e. nonlinear) polynomial equation. For both newborn groups, the fit obtained using a second-order equation (solid and dashed lines, Fig. 2) was a significantly better than the fit obtained using a first-order equation, as judged by the lower residual sums of squares ( $F$ test for the significance of added parameters, $p<$ $0.05)$. Second-order fits also were significantly better than firstorder fits for hypercarbic 1 -mo-olds but not for normocarbic 1mo-olds.

It is important not to overinterpret the meaning of the solid curves presented in Figure 2. Our main purpose in using the second-order polynomial was to test our contention that the relationship between [lactate] $]_{\text {rinal }}$ and [glucose $]_{\text {plasma }}$ is nonlinear and to provide optimal estimates for the value of the intercept for the plots shown in Figure 2, using the entire set of experimental data (see below). The underlying mechanism responsible for the nonlinear relationship between [lactate] final and [glucose $_{\text {plusma }}$ is not provided by polynomial equations. To interpret the nonlinear relationship between [lactate] $]_{\text {linal }}$ and [glucose] plisma in terms of physiologically meaningful parameters, we performed an analysis based on the theory for cerebral glucose transport using equation 2. The intercepts from the above mentioned second-order fits (see legend to Fig. 2) were used in the estimation of [glucose] $]_{\text {hrain }}$ using equation 3 , and plots of [glucose] brain versus [glucose] (Fig. 3). Using nonlinear regression analysis, equation 2 was fit to these data (dashed and solid lines in Fig. 3) to evaluate $\mathrm{K}_{1}$ and $T_{\max }$ relative to $V_{\text {glu. }}$. The results of these fits (Table 2) reveal substantially lower $\mathrm{K}_{\mathrm{t}}$ and $\mathrm{V}_{\mathrm{glu}} / \mathrm{T}_{\max }$ ratio for normocarbic newborns compared with 1 -mo-olds. These differences disappear for the hypercarbic newborn and 1-mo-old piglets, whose $K_{t}$ and $\mathrm{V}_{\mathrm{glu}} / \mathrm{T}_{\max }$ ratios were not different from each other. Hypercarbia produced changes in $\mathrm{K}_{\mathrm{t}}$ and $\mathrm{V}_{\mathrm{glu}} / \mathrm{T}_{\max }$ compared with normocarbia for either age group, but the changes are in the opposite direction. Whereas hypercarbic 1-mo-olds had a lower $\mathrm{K}_{\mathrm{t}}$ and $\mathrm{V}_{\mathrm{glu}} / \mathrm{T}_{\max }$ ratio $(25 \%$ and $12 \%$, respectively) compared with normocarbic 1-mo-olds, for newborns $\mathrm{K}_{\mathrm{t}}$ and the $\mathrm{V}_{\mathrm{glu}} / \mathrm{T}_{\max }$ ratio appeared to increase by $75 \%$ and $30 \%$, respectively.

The constancy in the brain lactate-' $\mathrm{H}$ NMR signal from 20 to 30 min after cardiac arrest (Fig. 1) indicates that cerebral reserves of glucose and glycogen were exhausted within the first 20 min of complete cerebral ischemia. Previous experiments have shown that the concentrations of glycolytic intermediates after ischemia remain less than $0.2 \mu \mathrm{mol} \cdot \mathrm{g}^{-1}$ with the exception of glycerol-P that increased in parallel with lactate at a ratio of $1: 24$, glycerol-

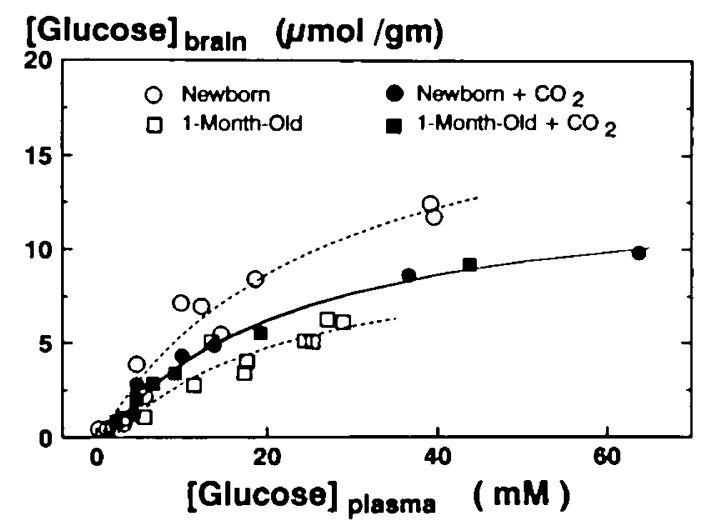

Fig. 3. The relationship between brain glucose concentration ([G/ltcose $\left.]_{\text {hrain }}\right)$ and blood plasma glucose concentration $\left([\text { Glucose }]_{\text {plusma }}\right.$ ) for newborn and 1-mo-old piglets in the presence and absence of hypercarbia. The solid lines represent the best fit by nonlinear regression analysis using equation 2. The best fit $\mathrm{V}_{\mathrm{glu}} / \mathrm{T}_{\max }$ and $\mathrm{K}_{1}$ values used to generate the solid lines are summarized in Table 2. 
Table 2. Comparison of $V_{g l u} / T_{\max }$ and $K_{t}$ for newborn and 1 -mo-old piglets during normocarbia and hypercarbia*

\begin{tabular}{|c|c|c|c|c|}
\hline & \multicolumn{2}{|c|}{ Normocarbia } & \multicolumn{2}{|c|}{ Hypercarbia } \\
\hline & $\begin{array}{l}\text { Newborn } \\
(n=11)\end{array}$ & $\begin{array}{l}\text { 1-mo-old } \\
(n=10)\end{array}$ & $\begin{array}{c}\text { Newborn } \\
(n=7)\end{array}$ & $\begin{array}{c}\text { 1-mo-old } \\
(n=7)\end{array}$ \\
\hline $\begin{array}{l}\mathrm{V}_{\mathrm{Blu}} / \mathrm{T}_{\text {max }} \\
\mathrm{K}_{\mathrm{t}}(\mathrm{mM})\end{array}$ & $\begin{array}{c}0.12 \pm 0.04+\neq \$ \\
2.8 \pm 1.5 \dagger\end{array}$ & $\begin{array}{c}0.30 \pm 0.03 \ddagger \| \S \\
4.5 \pm 1.4 \|\end{array}$ & $\begin{aligned} 0.21 & \pm 0.03+\| \\
3.7 & \pm 0.8\end{aligned}$ & $\begin{aligned} 0.23 & \pm 0.01 \dagger \| \\
4.0 & \pm 0.4\end{aligned}$ \\
\hline
\end{tabular}

* Values are best-fit value $\pm \mathrm{SD}$.

+ Significant difference compared with 1-mo-old normocarbic piglets (Duncan multiple comparison test. $p<0.05$ ).

$\ddagger$ Significant difference compared with newborn hypercarbic piglets (Duncan multiple comparison test, $p<0.05$ ).

$\S$ Significant difference compared with 1 -mo-old hypercarbic piglets (Duncan multiple comparison test. $p<0.05$ ).

$\|$ Significant difference compared with newborn normocarbic piglets (Duncan multiple comparison test. $p<0.05$ ).

P:lactate (5). These results suggest that errors in the calculation of [glucose $]_{\text {hrain }}$ due to incomplete hydrolysis of intracellular glucose or high postmortem concentrations of glycolytic intermediates would be negligibly small. However, glucose in whole blood undergoes slow glycolysis at a rate of approximately $3 \%$ per $\mathrm{h}$ in adults and approximately $26 \%$ per $\mathrm{h}$ in newborns (18); therefore, we expected some glucose to still be present in the brain tissue at the end of the NMR experiment. Enzymatic assays of postmortem brain tissue confirmed that [glucose] brain $_{\text {ranged }}$ from 0.2 to $4 \mu \mathrm{mol} \cdot \mathrm{g}^{-1}$ and increased as a function of the preischemic [glucose] $]_{\text {plasma. }}$. The concentration of glucose remaining was consistent with that expected from glucose present in the cerebral vasculature, assuming a cerebral blood volume corresponding to $3 \%$ to $6 \%$ of the total brain volume. We considered the possibility that glucose converted to lactate in the cerebral vasculature after the initiation ischemia could result in an overestimation of [glucose] brain because [glucose] brain was calculated from [lactate $]_{\text {final }}$ (see equation 3 ). Because hypercarb:a increases cerebral blood volume, this overestimation would be higher in animals that were made hypercarbic before ischemia. To estimate the maximum effect this could have on the transport constants in Table 2, we assumed that, as a worst case, the fraction of brain volume corresponding to cerebral blood volume equaled 0.04 and 0.09 for normocarbic and hypercarbic animals, respectively (19), and that all glucose remaining in the blood was converted to lactate within $40 \mathrm{~min}$. We then corrected the calculated [glucose $_{\text {brain }}$ values by subtracting the preischemia [glucose] $]_{\text {plasma }}$ by one of these two fractions, and refit equation 2 to the revised [glucose] brain versus [glucose] $]_{\text {plasma }}$ data sets for the four groups. The revised $\mathrm{V}_{\max } / \mathrm{T}_{\max }$ ratios were only slightly increased in all four age groups by 0.02 to 0.05 units compared with the values reported in Table 2 . The revised $K_{t}$ values for normocarbic animals also were slightly decreased $\left(K_{1}=2.6 \pm 1.4\right.$ and $3.9 \pm$ $1.3 \mathrm{mM}$ for newborn and 1 -mo-old piglets, respectively). For hypercarbic animals, the revised $K_{1}$ values showed larger reductions $\left(\mathrm{K}_{\mathrm{t}}=1.9 \pm 1.2\right.$ and $\left.2.6 \pm 0.2\right)$ because the correction factor for cerebral blood volume was approximately 2.2 times more than applied to the data collected for normocarbic animals. However, the use of "corrected" [glucose] brain values does not alter the major conclusions made in the preceding paragraph; normocarbic 1-mo-olds have significantly higher $K_{1}$ and $V_{\max } /$ $\mathrm{T}_{\max }$ ratios compared with normocarbic newborns, and these age-related differences diminish in the presence of hypercarbia.

Agonal glycolytic rates. The AGR calculated using equation 4 was dependent on [glucose] $]_{\text {plasma }}$ for both newborn and 1-mo-old hypercarbic piglets with distinct differences compared with each other and compared with normocarbic piglets (Fig. 4). Nonlinear regression analysis of $\mathrm{AGR}$ versus [glucose] plasma using equation 5 revealed no significant differences in the $V_{\max }$ and $K_{m}$ values measured for normocarbic and hypercarbic newborns (Table 3 ). In contrast, 1-mo-old hypercarbic piglets had significantly lower $V_{\max }$ and $K_{m}$ values compared with normocarbic 1-mo-old piglets. The hypercarbic 1-mo-old piglets had significantly higher $V_{\max }$ values compared with hypercarbic newborns, whereas $K_{m}$ was not different. Normocarbic 1 -mo-old piglet had significantly

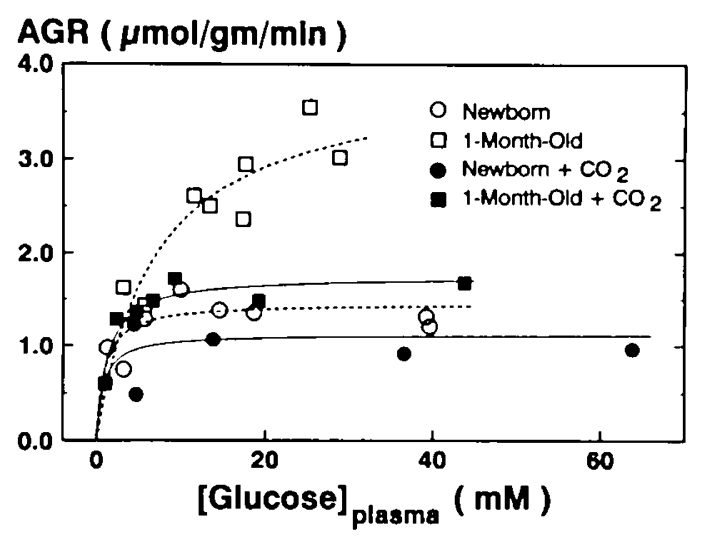

Fig. 4. Dependence of AGR on plasma glucose concentration ([G/H('ose $]_{\text {plasmus }}$ at the initiation of total ischemia. Different symbols are used to represent piglets of four different age groups (see Table 1). The solid line's represent the best fit by nonlinear regression to the data using equation 5; best fit $\mathrm{V}_{\max }$ and $\mathrm{K}_{\mathrm{m}}$ values are summarized in Table 3 .

higher $V_{m a x}$ and $K_{m}$ values compared with normocarbic newborns in agreement.

\section{DISCUSSION}

Differences in physiologic readings for newborn and 1-mo-old piglets during hypercarbia were small and unlikely to produce differential effects on cerebral glucose transport measured before ischemia or AGR measured during ischemia. We drew similar conclusions previously for normocarbic newborns and 1mo-old piglets (8). The [glucose] $]_{\text {plasma }}$ of both newborn and 1mo-old piglets was constant throughout the 20 -min period of hypercarbia, and the degree of hypercarbia resulting from the inhalation of $8 \%$ to $10 \% \mathrm{CO}_{2}\left(\mathrm{PCO}_{2}\right.$ approximately $\left.14 \mathrm{kPa}\right)$ was identical and constant for both age groups. Overall, these results show that the severity of hypercarbia was well matched for the two age groups and that a steady state of elevated $\mathrm{PCO}_{2}$ and modified [glucose] $]_{\text {plasma }}$ was achieved. As discussed previously ( 8 , 16) 10 to $20 \mathrm{~min}$ is considered sufficient time to ensure equilibration of glucose exchange between blood and brain before ischemia.

The additional data collected for normocarbic piglets in the present study lead us to change our perspective about age-related differences in the potential for brain lactate formation during complete ischemia. Previously, we concluded that hyperglycemic-normocarbic newborn and 1 -mo-old piglets would generate similar high concentrations of lactate during complete ischemia (8). This conclusion was based on the similarity of slopes measured for different age groups of piglets from plots of the postmortem [lactate] final versus preischemia [glucose] $]_{\text {plasma }}$ made for the entire range of [glucose] $]_{\text {plasma }}$ studied (8). As mentioned in Materials and Methods, the postmortem [lactate] final can be used as direct indicator of preischemia [glucose] $]_{\text {brain }}$ because the procedure to induce complete ischemia (cardiac arrest) converts the brain into a closed system. In the present study, the slope of 
Table 3. Comparison of $V_{\max }$ and $/ g /$ /ucose/plusma for $K_{m}$ for newborn and 1 -mo-old piglets during normocarbia and hypercarbia*

\begin{tabular}{|c|c|c|c|c|}
\hline & \multicolumn{2}{|c|}{ Normocarbia } & \multicolumn{2}{|c|}{ Hypercarbia } \\
\hline & $\begin{array}{l}\text { Newborn } \\
(n=8)\end{array}$ & $\begin{array}{c}\text { 1-mo-old } \\
(n=8)\end{array}$ & $\begin{array}{c}\text { Newborn } \\
(n=7)\end{array}$ & $\begin{array}{c}\text { 1-mo-old } \\
(n=7)\end{array}$ \\
\hline $\begin{array}{l}\mathrm{V}_{\max }\left(\mu \mathrm{mol} \cdot \mathrm{g}^{-1} \cdot \mathrm{min}^{-1}\right) \\
\mathrm{K}_{\mathrm{m}}(\mathrm{mM})\end{array}$ & $\begin{array}{l}1.46 \pm 0.14 \dagger \\
0.93 \pm 0.66 \dagger\end{array}$ & $\begin{array}{l}3.93 \pm 0.55 \neq \$ \| \\
6.86 \pm 3.00 \ddagger \$ \|\end{array}$ & $\begin{array}{l}1.12 \pm 0.22 \dagger \| \\
0.80 \pm 1.14 \dagger\end{array}$ & $\begin{array}{l}1.75 \pm 0.11+\$ \\
1.27 \pm 0.41 \dagger\end{array}$ \\
\hline
\end{tabular}

* Values are best-fit value \pm SD.

+ Significant difference compared with 1 -mo-old normocarbic piglets (Duncan multiple comparison test, $p<0.05$ ).

$\ddagger$ Significant difference compared with newborn normocarbic piglets (Duncan multiple comparison test, $p<0.05$ ).

$\S$ Significant difference compared with newborn hypercarbic piglets (Duncan multiple comparison test, $p<0.05$ ).

$\|$ Significant difference compared with 1-mo-old hypercarbic piglets (Duncan multiple comparison test, $p<0.05$ ).

plots of [lactate $]_{\text {final }}$ versus preischemia [glucose $_{\text {plasma }}$ for the subset of data where [glucose] $]_{\text {plasma }}<20 \mathrm{mM}$ was significantly higher for newborns compared with 1-mo-old piglets, implying that higher levels of [glucose] brain were present in newborns compared with 1-mo-old piglets. This is further supported by recent in vitro assays of glucose in brain tissue funnel-frozen under control conditions for normoglycemic piglets of different ages. Whereas the [glucose $]_{\text {hrain }} /[\text { glucose }]_{\text {glasma: }}$ concentration ratio equaled $0.36 \pm 0.03$ for 1 -mo-old normoglycemic piglets, this ratio equaled $0.74 \pm 0.16$ for newborns (20). Overall, these results

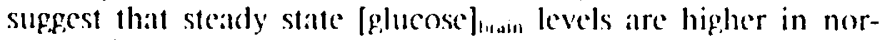
mocatbic newborns compated with 1-mo-old piglets, especially

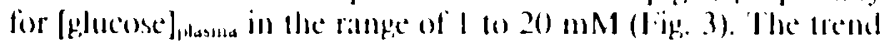

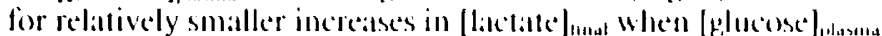

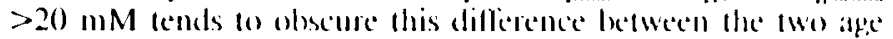
froups, as in our previous study where lle dalta wefe considered

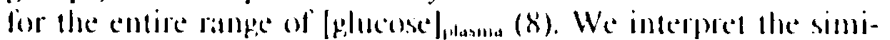

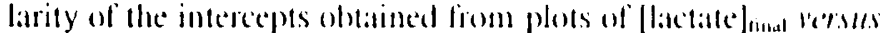

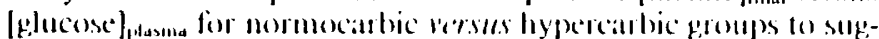

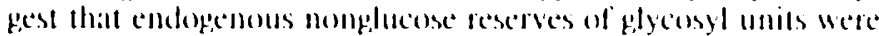
unallected by acule hypefplyeemia or hypereabiat. Ihis is consistent with previous studies of rats in which no significant atente changes in brain glyeogen concentation wete observed alled

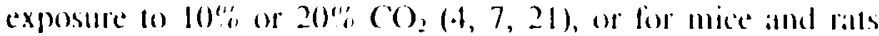
infused with glucose (22). This, plus the obscrvation of high linear correlations between [latetate] timal and [elucosed

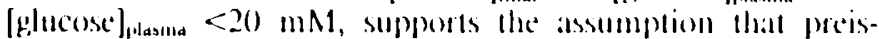

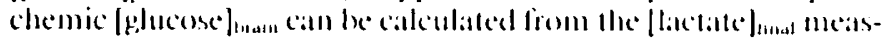
ured in postmorlem brain tissue simples using expattion 3 .

Recently, lactate and glyeogen determinations wete make for newborn and 1-mo-old piglets from heain tissuc fored under

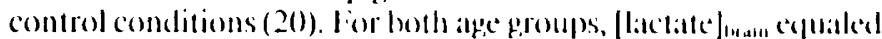

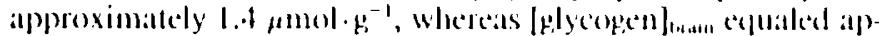
proximately 1.0 and 1.8 pmol.g. ' for newborn and l-mo-olds, respectively. (iiven this baseline flactate $\left.\right|_{\text {wain }}$ and assuming, that 2.9 latetate molecules are generated per molecule of gilyeofen during anaterobic plycolysis (5), we estimated contribution by

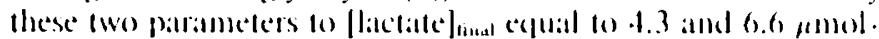
$\mathrm{g}^{-1}$ for newborn and 1-mo-olds, respectively. The latler concentration is in excellent afrecement with the interecpts estimated for 1-mo-olds in ligure 2. The former concentration is approximatcly $4 \mu m o l \cdot g^{-1}$ lower than the interepts estimaled for newborns, sufgesting that approximately $2 \mu m$ mol $g^{-1}$ of plycosyl units contribute to [tactate] timal from a souter not originating from preischemic cellular gilucose, gilycopen, and lactatc. This implies that the sum of preischemia concentration of ofleet hexoses of gilycolytic infermediates is higher in newhoren complated will 1mo-old piglets.

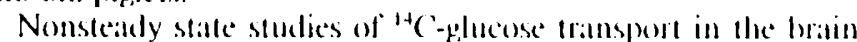
of adult and suchling rats indicate lhat $k_{1}$ does not change with age $(2.3,2.4) .11$ is important to note that the $k$, values in Table 2 are not directly comparable to the values reported in these two studies becatuse the latler were derived fiom nonsteady state tracer studies (16). Steatly state measurements of $K_{1}$ are avialiable only for adult bran and anger from 2 to $7 \mathrm{mMl}$, with fairly promineme species vartiations ( 16$)$. The steatly state me:tsurement of $K_{t}$ in the present study for normocarbic newborns was lower than 1 -mo-olds, suggesting that the affinity of the glucose transporter may increase slightly over this interval. It is conceivable that this could reflect ontogenetic changes in the brain glucose transporter (25). However, the relatively low values for $K_{t}$ in both newborn and 1 -mo-olds during either hypercarbia or normocarbia suggests that under normoglycemic or hyperglycemic conditions, the glucose transporter will be nearly saturated and operating at its maximal rate, $\mathrm{I}_{\text {max }}$.

The present study does not provide direct information on agerelated changes in either $T_{\text {ma }}$ or $V_{\text {ema }}$ hecause only the ratio $V_{\text {gut }} /$ $T_{\text {man }}$ is calculated. Non-steady statce metisutements of pllacose

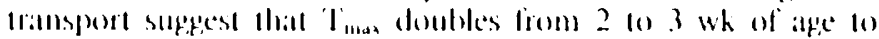

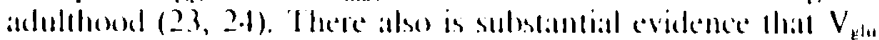
incerases with bain maturation $(2,5,6,20)$. For cillet hyper-

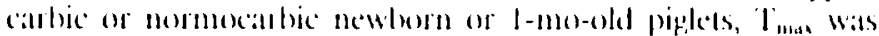

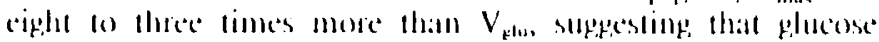
tamsport into the brain was not the rate-limiting step for follecose utilization, consistent with previous reports of atult bratin (16).

The functional form of efuation 2 illustrates an important

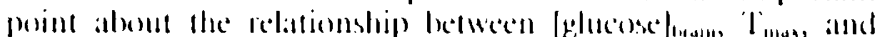

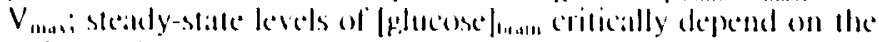

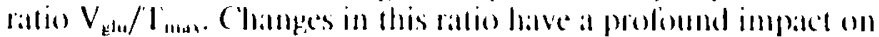

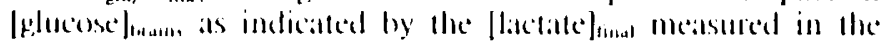
pesent experiments. For example, newhorns had a latger in-

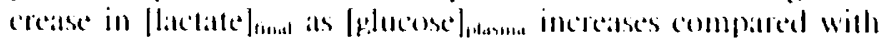
I-mo-olds. This phenomenom is primatrily at conseguence of at

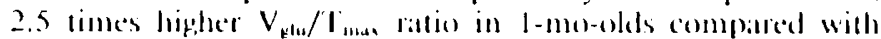
newhorns. The higher rate of glacose utilization relative to transport in I-mo-olds creates at stronger "medatholic sinh" that lowers |ylucose |

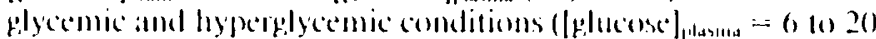

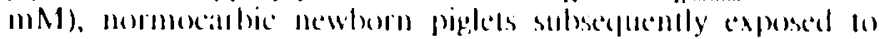

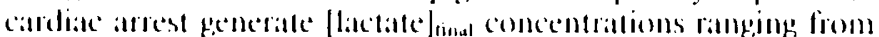
I0 to $25 \mu \mathrm{mol} \cdot \mathrm{g}^{-1}$ compatred with $9101.5 \mu \mathrm{mol} \cdot \mathrm{g}^{-1}$ for $1-\mathrm{mol}-$ olds (ligg. 2). An important consecpuence is that mewhorn pighels subjected fo complele ischemia for a sulficient duration combl have brain latelate concentrations associalted will atcidosis-ent-

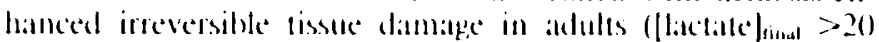

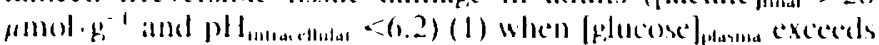

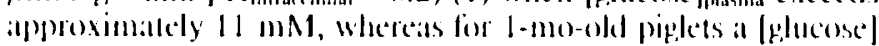

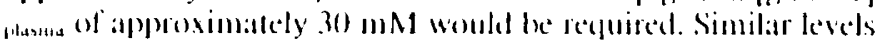
of brain lactale during complete ischemia lesult in similar levels of hatin acidosis for cither newboren of 1-mo-old piglets because the physiochemical acid bullering eapacily of bean does not chatoge during this period (12). Thus, it would secol prudent to

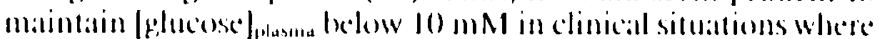
complete of neart-complete ischemia could ocecur.

Ilypercatibia produced substantially difledent changes in the

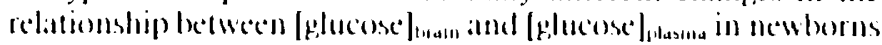
companed will 1-mo-old piplets (lig.. 3). lor newborn and Imo-old pifplets, loypereathia had no significant eflect on $K_{1}$. However, whereas hyperciabia decreased the $V_{\text {elua }} / l_{\text {itas }}$ ratio by

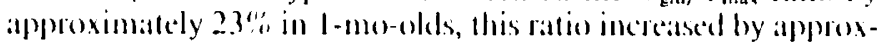
imately 75\%, in newborns. The allect that hypereatbia has on

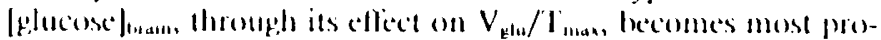


nounced during hyperglycemia. This is illustrated in Figures 2 and 3: when [glucose] plasma exceeds $10 \mathrm{mM}$, the difference between [lactate] final or [glucose] brain in hypercarbic versus normocarbic animals was most prominent. In newborns, hypercarbia lowered [glucose $]_{\text {hrain }}$ and hence lowered [lactate] finat in animals subsequently exposed to ischemia. This could translate into a greater beneficial effect for hypercarbic newborns compared with normocarbic newborns because lactic acidosis would be decreased in the former compared with the latter. For example, a [lactate] final equal to $20 \mu \mathrm{mol} \cdot \mathrm{g}^{-1}$ will be reached at a [glucose] $]_{\text {plasma }}$ of approximately $18 \mathrm{mM}$ in hypercarbic newborns, whereas this same concentration of lactate is reached at only 11 $\mathrm{mM}$ in normocarbic newborn piglets. In contrast to newborns, hypercarbia moderately raises [glucose] $]_{\text {hrain }}$ for hyperglycemic compared with normocarbic 1-mo-old piglets. Higher preischemia [glucose] brain may be detrimental because this would result in higher levels of lactic acidosis during complete ischemia. However, the slower formation of detrimental levels of lactic acidosis in hypercarbic 1-mo-olds compared with normocarbic 1-mo-olds could provide a more important beneficial effect for acute ischemic episodes (see below).

Relatively few studies have been performed to measure glucose utilization during complete ischemia. This reflects the technical difficulties and the cost associated with accurately measuring the time course of lactate formation using in vitro sampling techniques that supply one time point per animal $(5,9,20)$. We are aware of only one previous study (4) that measured AGR in adult rat brain after complete ischemia induced via decapitation during steady states of normocapnia $(5.2 \mathrm{kPa})$ versus mild hypercapnia $(8.1 \mathrm{kPa})$. AGR was $6.24 \pm 0.82$ and $4.80 \pm .96 \mu \mathrm{mol}$. $\mathrm{g}^{-1} \cdot \mathrm{min}^{-1}$ in normocarbic and hypercarbic groups, respectively, corresponding to a $23 \%$ reduction. Given the milder degree of hypercapnia compared with the present study and noting that [glucose] $]_{\text {plasma }}$ for the two groups was 10.6 and $12.8 \mathrm{mM}$, respectively, the reduction observed in the previously mentioned study (4) is similar to that observed for 1-mo-old piglets in the present study.

Glucose utilization during ischemia was measured after a 20 min period when [glucose] $]_{\text {plasma }}$ was constant; therefore, $K_{m}$ and $\mathrm{V}_{\max }$ reflect rate-limiting reactions for agonal glycolysis inside the cell. Hexokinase is thought to be a key enzyme controlling the increased glycolytic rate during ischemia $(5,16)$. The binding affinity of glucose for hexokinase $\left(\mathrm{K}_{\mathrm{hex}}\right)$ is approximately 0.05 $\mathrm{mM}$, and, therefore, the $\mathrm{K}_{\mathrm{m}}$ values in Table 3 are much higher than $\mathrm{K}_{\text {hex }}$ expected in brain. However, $\mathrm{K}_{\mathrm{m}}$ was determined from plots of AGR versus [glucose] $]_{\text {plasma }}$ not [glucose $]_{\text {hrisin. }}$. Therefore, based on the theoretical relationships presented in Figures 3 and 4 , we calculated a set of 15 AGR versus [glucose] $]_{\text {brain }}$ data points for each of the four groups of piglets and determined $V_{\max }$ and $K_{m}$ using equation 6 . The relationship between AGR and [glucose $]_{\text {hrain }}$ was similar to the plots shown in Figure 4, with the exception that the curves for the four different groups are steeper and are shifted to the left. $V_{\max }$ was not substantially different from the values shown in Table 3 (1.34 \pm 0.04 and $3.59 \pm 0.29$ $\mu \mathrm{mol} \cdot \mathrm{g}^{-1} \cdot \mathrm{min}^{-1}$ for newborn and 1 -mo-old normocarbic animals, respectively, and $1.03 \pm 0.02$ and $1.48 \pm 0.06 \mu \mathrm{mol} \cdot \mathrm{g}^{-1}$. $\mathrm{min}^{-1}$ for newborn and 1 -mo-old hypercarbic animals, respectively), but $\mathrm{K}_{\mathrm{m}}$ was shifted to lower values for all four groups $(0.32 \pm 0.05$ and $1.31 \pm 0.29 \mathrm{mM}$ for newborn and 1 -mo-old normocarbic animals, respectively, and $0.12 \pm 0.02$ and $0.09 \pm$ $0.03 \mathrm{mM}$ for newborn and 1 -mo-old hypercarbic animals, respectively). The correction for potential overestimation of [glucose $]_{\text {brain }}$ due to the conversion of cerebral blood glucose to lactate (see Results) resulted in slightly lower $\mathrm{K}_{\mathrm{m}}$ estimates for normocarbic animals $(0.29$ and $1.27 \mathrm{mM}$ for newborns and 1 -mo-olds, respectively), and slightly higher estimates for hypercarbic animals $(0.27$ and $0.18 \mathrm{mM}$ for newborns and 1-mo-olds, respectively). All calculated $\mathrm{K}_{\mathrm{m}}$ values are higher than literature estimates of $K_{\text {hex }}$, especially for normocarbic 1-mo-olds. Presently, it is unclear whether the difference between $K_{m}$ and $K_{h c x}$ is a reflection of species differences in the value of $\mathrm{K}_{\text {hex }}$ in swine compared with rodents, experimental differences in the manner in which $\mathrm{K}_{\mathrm{m}}$ was calculated (in vivo versus in vitro), or that there is a control point for the glucose modulation of $A G R$ other than hexokinase. Further experiments to evaluate the enzymatic properties of hexokinase in swine brain could help clarify this issue.

As illustrated in Figure 4, AGR is strongly influenced by [glucose $]_{\text {nlasma }}$ to different degrees depending on both age and the absence or presence of hypercarbia. The additional data collected for two hyperglycemic normocarbic newborn and two 1-mo-old piglets resulted in slightly higher estimates of $\mathrm{K}_{\mathrm{m}}$ and $\mathrm{V}_{\max }$ compared with our previous study (8). However, as in the previous study, both $\mathrm{V}_{\max }$ and $\mathrm{K}_{\mathrm{m}}$ were significantly higher in 1mo-old normocarbic piglets compared with normocarbic newborns. Whereas hypercarbia decreases $V_{\max }$ and $K_{m}$ slightly in newborns, these quantities showed prominent decreases in 1 mo-olds. Thus, during ischemia in hyperglycemic animals ([glu$\operatorname{cose}]_{\text {flasma }}>20 \mathrm{mM}$ ), hypercarbia reduces the rate of lactate accumulation by up to $55 \%$ in 1 -mo-old piglets but only by $23 \%$ in newborns. For normoglycemic or hypoglycemic animals (Iglucose $]_{\text {nlasma }}<6 \mathrm{mM}$ ), hypercarbia will decrease rates of lactate accumulation to the about same degree in newborn and 1-moold animals. Several recent in vivo ${ }^{31} \mathrm{P}$ NMR studies of the cerebral metabolic consequences of hypercarbia using adult animal models from various species have been reported (26-29). These studies all report a decrease in $\mathrm{pH}_{\text {intracellutar that should }}$ inhibit glycolysis and an increase in inorganic phosphate that should stimulate glycolysis (30). Given the observation that hypercarbia decreases AGR in adult rats (4), it is possible that the metabolic effects of a decrease in $\mathrm{pH}_{\text {intracellular }}$ predominate over the increase in inorganic phosphate to produce a net inhibitory effect. Less certain is the effect of hypercarbia on cerebral ADP and AMP concentrations, with one study suggesting an increase (26), two suggesting no change $(27,28)$, and one suggesting a decrease (29). Decreases in $\mathrm{pH}_{\text {intracellular }}$ and increases in inorganic phosphate also have been reported for immature brain $(31,32)$; however, changes in ADP and AMP have not been reported. Currently, it is unclear whether age-related difference in the magnitude of changes in $\mathrm{pH}$, inorganic phosphate. ADP. or AMP induced by hypercarbia could account for the difference that hypercarbia had on AGR for newborn versus 1-mo-old piglets in the present study. Further studies of potential agerelated differences in the effect that hypercarbia has on $\mathrm{pH}_{\text {intracellular }}$ or phosphorylated metabolite concentrations using in vivo ${ }^{31} \mathrm{P}$ NMR could help clarify this issue.

In conclusion, these results demonstrate that both brain maturation and [glucose] plasma $_{\text {are critical factors to consider when }}$ assessing the effects of hypercarbia. To the extent that it reduced the rate of lactate formation and [lactate $]_{\text {final }}$, hypercarbia could prove beneficial because both [glucose $]_{\text {brain }}$ and AGR were reduced in newborns and AGR was reduced in 1-mo-olds with only a marginal increase in [glucose $]_{\text {brain }}$. These effects were most prominent in animals who were made hyperglycemic before ischemia was initiated. Under these conditions, hypercarbia could help reduce brain lactic acidosis to levels below the critical threshold thought to be associated with enhanced irreversible tissue damage (1). However, the putative benefit realized from the direct effects of hypercarbia on brain lactate formation must be interpreted with caution because in clinical settings acute hypercarbia is normally viewed as undesirable (2). Hypercarbia often implies serious cardiovascular instability and could be detrimental by increasing the incidence of intraventricular hemorrhage or altering blood flow regulation.

Acknowledgment. Dr. Corbett thanks the Departments of Pediatrics and Radiology for their continuing support, which made this study possible. 


\section{REFERENCES}

1. Rehncrona S 1985 Brain acidosis. Ann Emerg Med 14:770-776

2. Volpe JJ 1987 Hypoxic-ischemic encephalopathy: basic aspects and fetal assessment. In: Volpe JJ (ed) Neurology of the Newborn. WB Saunders, Philadelphia, pp 160-195

3. Miller AL 1985 Carbon dioxide narcosis. In: McCandless DW (ed) Cerebra Energy Metabolism and Metabolic Encephalopathy. Plenum Press. New York, pp 143-162

4. Kogure K, Busto P, Scheinberg P, Reinmuth O 1975 Dynamics of cerebral metabolism during moderate hypercapnia. J Neurochem 24:471-478

5. Lowry OH, Passonneau JV, Hasselberger FX, Schultz DW 1964 Effect of ischemia on known substrates and cofactors of the glycolytic pathway in brain. J Biol Chem 239:18-30

6. Holowach-Thurston J, McDougal DB 1969 Effect of ischemia on metabolism of the brain of the newborn mouse. Am J Physiol 216:348-352

7. Folbergrova J, MacMillan V, Siesjo BK 1972 The effect of hypercapnic acidosis upon some glycolytic and Krebs cycle-associated intermediates in the rat brain. J Neurochem 19:2507-2517

8. Corbett RJT, Laptook AR, Ruley JI, Garcia D 1991 The effect of age on glucose dependent changes in agonal cerebral glycolytic rates. Pediatr Res 30:579-586

9. Petroff OAC, Prichard JW, Ogino T, Shulman RG 1988 Proton magnetic resonance spectroscopy studies of agonal carbohydrate metabolism in rabbi brain. Neurology 38:1569-1574

10. Linderkamp O, Betke K, Guntner M, Jap GH, Riegel KP, Walser K 1981 Blood volume in newborn piglets: effects of time of natural cord rupture. intra-uterine growth retardation, asphyxia, and prostaglandin-induced prematurity. Pediatr Res 15:53-57

11. Benedetti C, Butler SH 1990 Systemic analgesia. In: Benica JJ (ed) The Management of Pain. Volume II Lea \& Febiger, Philadelphia, pp 1640-1675

12. Corbett RJT, Laptook AR, Garcia D. Ruley JI 1992 Cerebral acid bufferin capacity at different ages measured in vivo by ${ }^{31} \mathrm{P}$ and ${ }^{1} \mathrm{H}$ nuclear magnetic resonance spectroscopy. J Neurochem 59:216-226

13. Corbett RJT, Laptook AR 1990 Acid homeostasis and partial ischemia in neonatal piglet brain. J Neurochem 54:1208-1217

14. Lowry OH, Passonneau JV 1972 A Flexible System of Enzymatic Analysis. Academic Press, New York

15. Duncan DB 1955 Multiple range and multiple $F$ tests. Biometrics 11:1-42

16. Lund-Andersen H 1979 Transport of glucose from blood to brain. Physiol Rev 59:305-352

17. Gatfield PD, Lowry OH, Schultz DW, Passoneau JV 1966 Regional energy reserves in mouse brain and changes with ischemia and anaesthesia. J Neurochem 13:185-195
18. Meites S, Bohman N 1963 In vitro stabilization of blood glucose with water. Clin Chem 9:594-599

19. Mosley ME, Chew WM, White DL, Kucharczyk J, Litt L, Derugin N, Dupon J. Brasch RC, Norman D 1992 Hypercarbia-induced changes in cerebral blood volume in the cat: a 'H MRI and intravascular contrast agent study. Magn Reson Med 23:21-30

20. Corbett RJT, Laptook AR, Garcia D, Ruley JI 1993 Energy reserves and utilization rates in developing brain measured in vivo by ${ }^{31} \mathrm{P}$ and $1 \mathrm{H}$ nuclear magnetic resonance spectroscopy. J Cereb Blood Flow Metab 13:235-246

21. Miller AL. Hawkins RA, Veech RL 1975 Decreased rate of glucose utilization by rat brain in vivo after exposure to atmospheres containing high concentrations of $\mathrm{CO}_{2}$. J Neurochem 25:553-558

22. Nelson SR, Schultz DW, Passoneau JV, Lowry OH 1968 Control of glycogen levels in brain. J Neurochem 15:1271-1279

23. Cremer JE, Cunningham VJ, Pardridge WM, Braun LD, Oldendorf WH 1979 Kinetics of blood-brain barrier transport of pyruvate, lactate and glucose in suckling, weanling, and adult rats. J Neurochem 33:439-445

24. Daniel PM. Love ER. Pratt OE 1978 The effect of age upon the influx of glucose into the brain. J Physiol 274:141-148

25. Asano T Shibasaki Y, Kasuga M. Kanazawa Y Takaku F Akanuma Y, Oka Y 1988 Cloning of a rabbit brain glucose transporter and alterations of glucose transporter mRNA during tissue development. Biochem Biophys Res Commun 154:1204-1211

26. Nioka S, Chance B, Hilberman M, Subramanian HV Leigh JS, Veech RL. Forster RE 1987 Relationship between intracellular pH and energy metabolism in dog brain as measured by ${ }^{31}$ P NMR. J Appl Physiol 62:2094-2102

27. Petroff OAC, Prichard JW, Behar KL. Rothman DL. Alger JR, Shulman RG 1985 Cerebral metabolism in hyper- and hypocarbia: ${ }^{31} \mathrm{P}$ and ${ }^{1} \mathrm{H}$ nuclear magnetic resonance studies. Neurology 35:1681-1688

28. Nishimura M. Johnson DC. Hitzig BM, Okunieff P, Kazemi H 1989 Effects of hypercapnia on brain $\mathrm{pH}_{1}$ and phosphate metabolite regulation by ${ }^{31} \mathrm{P}$ NMR. J App! Physiol 66:2181-2188

29. Litt L. Gonzalez-Mendez R, Severinghaus JW. Hamilton WK. Rampil IJ, Shuleshko J, Murphy-Boesch J. James TL 1986 Cerebral intracellular ADP concentrations during hypercarbia: an in vivo "P nuclear magnetic resonance study in rats. J Cereb Blood Flow Metab 6:389-392

30. Erecinska M, Silver IA 1989 ATP and brain function. J Cereb Blood Flow Metab 9:2-19

31. Cady EB, Chu A, Costello AMD, Delpy DT, Gardiner RM, Hope PL, Reynolds EOR 1987 Brain intracellular $\mathrm{pH}$ and metabolism during hypercarbia in the newborn lamb. J Physiol 382:1-14

32. Corbett RJT Laptook AL. Hassan A, Nunnally RL 1988 Quantitation of acidosis in neonatal brain tissue using the ${ }^{31} \mathrm{P}$ NMR peak of phosphoethanolamine. Magn Reson Med 6:99-106 